\title{
Assisted ventilation in COPD - association between previous hospitalizations and mortality
}

\author{
This article was published in the following Dove Press journal: \\ International Journal of COPD \\ 3 May 2016 \\ Number of times this article has been viewed
}

\author{
Anne Pernille Toft- \\ Petersen ${ }^{1,2}$ \\ Christian Torp-Pedersen ${ }^{1,3}$ \\ Ulla Møller Weinreich ${ }^{1,4}$ \\ Bodil Steen Rasmussen ${ }^{1,2}$ \\ 'Department of Clinical Medicine, \\ Aalborg University, ${ }^{2}$ Department \\ of Anaesthesia and Intensive Care, \\ Aalborg University Hospital, \\ ${ }^{3}$ Department of Health, Science \\ and Technology, Aalborg University, \\ Aalborg, ${ }^{4}$ Department of Respiratory \\ Medicine, Aalborg University \\ Hospital, Denmark
}

Background: In general, previous studies have shown an association between prior exacerbations and mortality in COPD, but this association has not been demonstrated in the subpopulation of patients in need of assisted ventilation. We examined whether previous hospitalizations were independently associated with mortality among patients with COPD ventilated for the first time.

Patients and methods: In the Danish National Patient Registry, we established a cohort of patients with COPD ventilated for the first time from 2003 to 2011 and previously medicated for obstructive airway diseases. We assessed the number of hospitalizations for COPD in the preceding year, age, sex, comorbidity, mode of ventilation, survival to discharge, and days to death beyond discharge.

Results: The cohort consisted of 6,656 patients of whom $66 \%$ had not been hospitalized for COPD in the previous year, $18 \%$ once, $8 \%$ twice, and $9 \%$ thrice or more. In-hospital mortality was $45 \%$, and of the patients alive at discharge, $11 \%$ died within a month and $39 \%$ within a year. In multivariate models, adjusted for age, sex, mode of ventilation, and comorbidity, odds ratios for in-hospital death were 1.26 (95\% confidence interval [CI]: 1.11-1.44), 1.43 (95\% CI: 1.19-1.72), and 1.56 (95\% CI: 1.30-1.87) with one, two, and three or more hospitalizations, respectively. Hazard ratios for death after discharge from hospital were 1.32 (95\% CI: 1.19-1.46), 1.76 (95\% CI: 1.52-2.02), and 2.07 (95\% CI: 1.80-2.38) with one, two, and three or more hospitalizations, respectively.

Conclusion: Preceding hospitalizations for COPD are associated with in-hospital mortality and after discharge in the subpopulation of patients with COPD with acute exacerbation treated with assisted ventilation for the first time.

Keywords: pulmonary disease, chronic obstructive, respiration, artificial, patient readmission, hospital mortality, critical care

\section{Introduction}

COPD is a persistent, progressive airflow limitation associated with a chronic airway inflammation and is among the leading causes of mortality and morbidity worldwide, in fact predicted to be the third leading cause of death by $2020{ }^{1}$

An acute exacerbation of COPD (AECOPD), defined as worsening of symptoms beyond normal day-to-day variation, is associated with increased mortality. ${ }^{1-3}$ In general, exacerbations are more frequent in severe COPD, ${ }^{4,5}$ but recent studies show that the number of exacerbations varies extensively among patients with COPD with similar lung function in stable phases. Nevertheless, exacerbations are the best predictor of their own recurrence. ${ }^{3,4,6}$ It has been suggested that an inherent "frequent-exacerbation phenotype" with a distinct pathophysiology might explain at least parts of the extensive clinical variability. ${ }^{4,7}$ Previous accumulated exacerbations have been shown to predict
Correspondence: Anne Pernille ToftPetersen

Department of Clinical Medicine, Aalborg Universitetshospital, Sdr. Skovvej I5, 9000 Aalborg, Denmark

Tel +4597 $66 \quad 1864$

$\mathrm{Fax}+4597661902$

Email aptp@rn.dk (c) (1) (5) 2016 Toft-Petersen et al. This work is published and licensed by Dove Medical Press Limited. The full terms of this license are available at https://www.dovepress.com/terms.php cc) and incorporate the Creative Commons Attribution - Non Commercial (unported, v3.0) License (http://creativecommons.org/licenses/by-nc/3.0/). By accessing the work you hereby accept the Terms. Non-commercial uses of the work are permitted without any further permission from Dove Medical Press Limited, provided the work is properly attributed. For permission for commercial use of this work, please see paragraphs 4.2 and 5 of our Terms (https://www.dovepress.com/terms.php). 
not only new exacerbations but also mortality. This prediction is independent of stable phase lung function impairment, and mortality increases by each subsequent exacerbation. ${ }^{5,8-11}$ It is not known whether the association between previous exacerbations and mortality is independent of the degree of acute illness. Patients subjected to assisted ventilation constitute a group whose acute illness is severe, and the association between previous exacerbations and mortality in this group has not been elucidated.

The overall short-term mortality among patients with acute exacerbations ranges from $2.1 \%$ to $20.4 \%,{ }^{9,12,13}$ but patients with severe acute COPD admitted to intensive care unit (ICU) are particularly at risk with a 6-month mortality ranging from $25 \%$ to $40 \% .^{12,14,15}$ In-hospital mortality rates for patients being ventilated are 5\%-25\% but higher in relation to invasive mechanical ventilation (IMV) than to noninvasive mechanical ventilation (NIV). ${ }^{16-20}$ Predictors of mortality in hospitalized patients with COPD ${ }^{12,21,22}$ are age, comorbidities, and end-stage COPD with concomitant organ dysfunctions. Lung function impairment in stable phase is in itself a poor predictor of short-term mortality following exacerbations ${ }^{8,23}$ but is associated with long-term mortality. ${ }^{24}$ On the other hand, acidosis, which mirrors acute derangement, predicts short-term but not long-term mortality. ${ }^{12}$ In patients admitted to ICU, acute derangement is of major importance regarding both short-term ${ }^{25,26}$ and intermediate-term survival, ${ }^{15}$ but long-term survival studies have been conflicting with regard to independent risk predictors. ${ }^{14,27-31}$

The aim of this study was to investigate whether the frequency of previous hospitalizations for AECOPD can predict in-hospital mortality and mortality after discharge in an inception cohort of patients with COPD treated with assisted ventilation for the first time. We hypothesized that frequent COPD hospitalizations were associated with excess mortality following assisted ventilation.

\section{Patients and methods}

All hospitalizations from 2002 to 2011 were identified in the Danish National Patient Registry. Successive hospitalizations were merged if the discharge date of the first and the admission date of the second were identical. AECOPD hospitalizations were defined as hospitalizations with either a primary diagnosis of COPD (International Classification of Diseases, tenth edition [ICD-10]: DJ44) or a complex of either acute respiratory failure (ICD-10: DJ96) or pneumonia (ICD-10: DJ13-18) as the primary diagnosis and COPD as a secondary diagnosis as described by Thomsen et al. ${ }^{32}$ In general, hospitalizations related to diseases of the respiratory system (respiratory hospitalizations) were identified by a primary diagnosis within the entire ICD-10 DJ-spectrum. No attempts were made to distinguish between admissions for exacerbations with and without pneumonia. Patients $<30$ years of age were excluded to minimize inclusion of misclassified asthma. First time ventilation was defined as the first AECOPD hospitalization where assisted ventilation was performed, but first time ventilations in 2002 were discarded as no specific procedure code for NIV was accessible till 2003. In the National Register of Medicinal Product Statistics, all prescriptions in the year preceding first time hospitalizations were identified. By ATC code "R03", drugs for obstructive airway diseases were identified. First time ventilation was classified as the index hospitalization if a prescription was redeemed within 1 year before. Any patient with an index hospitalization was included in the cohort (Figure 1). Mode of ventilation at the

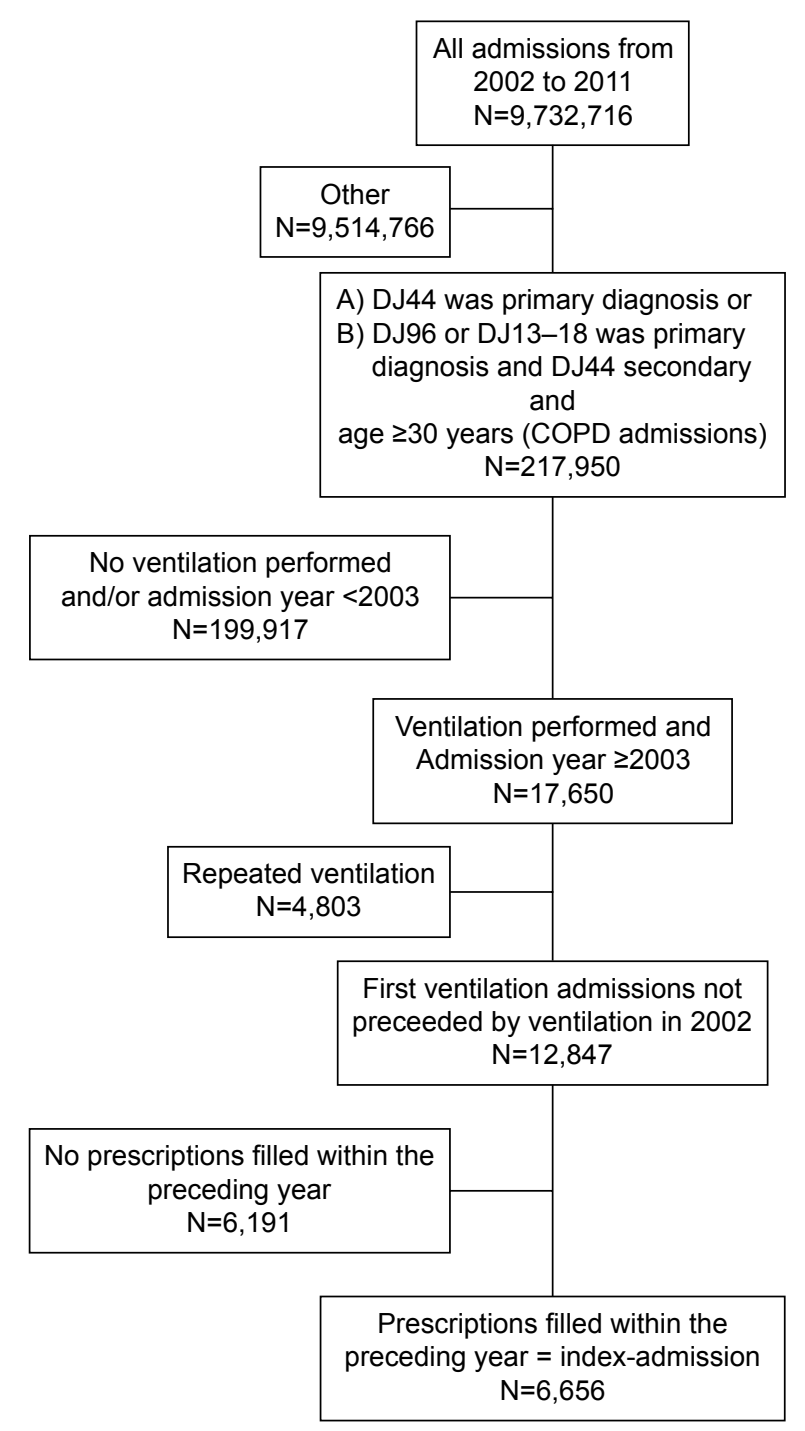

Figure I The inclusion of patients. 
index hospitalization was characterized as either "IMV" (BGDA0) or "NIV" (BGDA1). The categories were mutually exclusive and hierarchically assigned so that IMV overruled NIV, if both were registered.

The number of AECOPD and respiratory system-related hospitalizations in the year preceding the index hospitalization was counted. Charlson comorbidity score based on diagnoses made during hospitalizations and outpatient visits 10 years prior to the discharge from the index hospitalization were assigned to individual diseases ad modum Radovanovic et a ${ }^{33}$ and grouped in three with 1,2, or 3+ points, respectively, as per definition all patients received one point for having COPD.

Information on day of death was obtained from the Danish Civil Registration System. Each patient was followed until the time of death or censured by December 31, 2013. Informed consent was not required according to Danish legislation.

General characteristics between groups were compared by chi-square test (character variables) and Kruskal-Wallis test (continuous variable). For analysis of in-hospital mortality, logistic regression was used, and for analysis of mortality beyond discharge, Cox proportional hazards models were used. In both models, continuous variables were tested for linearity, and in the Cox model, dependency of the estimates on time was evaluated by the Schoenfeld residuals. Interactions a priori were considered relevant, that is, interactions between previous hospitalizations, and age, sex, and mode of ventilation, respectively, were tested for by comparisons of likelihood. $P$-values $<0.05$ were considered significant. Statistical analyses were performed in SAS 9.4C (SAS Institute Inc., Cary, NC, USA) and R $\odot$ Version 3.1.1.

\section{Results}

The population consisted of 6,656 patients (Table 1). Of these, $65 \%$ had not been hospitalized for AECOPD in the preceding year, $18 \%$ had been hospitalized once, $8 \%$ twice, and $9 \%$ thrice or more. The proportion excluded was $50 \%$ in the group of patients not hospitalized in the previous year and $44 \%, 41 \%$, and $45 \%$ in the group hospitalized once, twice, and thrice, respectively. Mortality rates are shown in Tables 2 and 3. The annual number of first time ventilations for COPD exacerbation increased from 355 in 2003 to 1,236 in 2011.

Increasing age, high Charlson comorbidity score, and IMV were the risk factors for in-hospital mortality. The risk decreased during the study period. For all patients, inhospital mortality was associated with the number of previous AECOPD hospitalizations. The odds ratios, compared to no previous hospitalizations, were 1.26 (95\% confidence interval [CI]: 1.11-1.44) with one hospitalization, 1.43 (95\% CI: 1.19-1.72) with two hospitalizations, and 1.56 (95\% CI: 1.30-1.87) with three or more hospitalizations (Figure 2). The risk associated with three or more hospitalizations was significantly higher than the risk associated with one hospitalization $(P=0.04)$.

Table I Characteristics of included patients at baseline by number of COPD hospitalizations in the previous year

\begin{tabular}{|c|c|c|c|c|c|}
\hline \multirow[t]{3}{*}{ Characteristics } & \multicolumn{4}{|c|}{ Number of admissions in the previous year } & \multirow[b]{2}{*}{ Total } \\
\hline & 0 & $\mathbf{I}$ & 2 & $3+$ & \\
\hline & $n=4,333$ & $\mathrm{n}=1,2 \mathrm{I} 3$ & $n=538$ & $n=572$ & $n=6,656$ \\
\hline \multicolumn{6}{|l|}{ Sex } \\
\hline Male & $2,48 \mathrm{I}(57.3 \%)$ & $684(56.4 \%)$ & 305 (56.7\%) & $320(55.9 \%)$ & $3,790(56.9 \%)$ \\
\hline \multicolumn{6}{|l|}{ Age, year } \\
\hline Median (IQR) & 74.I (66.4-79.8) & $74.8(67.5-80.6)$ & $73.9(67.1-80.0)$ & $72.9(65.1-77.9)$ & 74.I (66.5-79.8) \\
\hline \multicolumn{6}{|c|}{ Charlson comorbidity score } \\
\hline 1 & I,69I (39.0\%) & $429(35.4 \%)$ & $183(34.0 \%)$ & $216(37.8 \%)$ & $2,519(37.8 \%)$ \\
\hline 2 & $\mathrm{I}, 05 \mathrm{I}(24.3 \%)$ & $278(22.9 \%)$ & |3| (24.3\%) & $150(26.2 \%)$ & $1,610(24.2 \%)$ \\
\hline $3+$ & I,59I (36.7\%) & $506(41.7 \%)$ & $224(4 \mid .6 \%)$ & $206(36.0 \%)$ & $2,527(38.0 \%)$ \\
\hline \multicolumn{6}{|l|}{ Time period } \\
\hline 2003-2005 & $856(19.8 \%)$ & 247 (20.4\%) & $120(22.3 \%)$ & 133 (23.3\%) & I,356 (20.4\%) \\
\hline $2006-2008$ & 1,410 (32.5\%) & $412(34.0 \%)$ & 181 (33.6\%) & 191 (33.4\%) & $2,194(33.0 \%)$ \\
\hline 2009-20II & 2,067 (47.7\%) & 554 (45.7\%) & 237 (44.1\%) & 248 (43.4\%) & $3,106(46.7 \%)$ \\
\hline \multicolumn{6}{|l|}{ Mode of ventilation } \\
\hline NIV & $2,316(53.5 \%)$ & 726 (59.9\%) & $346(64.3 \%)$ & 389 (68.0\%) & 3,777 (56.7\%) \\
\hline \multicolumn{6}{|l|}{ Length of stay } \\
\hline I-2 days & 406 (9.4\%) & $126(10.4 \%)$ & 81 (15.1\%) & 64 (II.2\%) & 677 (10.2\%) \\
\hline $3-7$ days & I,023 (23.6\%) & $333(27.5 \%)$ & I 57 (29.2\%) & $178(31.1 \%)$ & I,69I (25.4\%) \\
\hline $7+$ days & $2,904(67.0 \%)$ & 754 (62.2\%) & 300 (55.8\%) & 330 (57.7\%) & $4,288(64.4 \%)$ \\
\hline
\end{tabular}

Abbreviations: IQR, interquartile rage; NIV, noninvasive mechanical ventilation. 
Table 2 In-hospital mortality by number of COPD hospitalizations in the previous year

\begin{tabular}{|c|c|c|c|c|c|}
\hline & \multicolumn{4}{|c|}{ Number of admissions in the previous year } & \multirow[b]{2}{*}{ Total } \\
\hline & 0 & $\mathbf{I}$ & 2 & $3+$ & \\
\hline & $n=4,333$ & $n=1,213$ & $n=538$ & $n=572$ & $n=6,656$ \\
\hline \multicolumn{6}{|l|}{ Mortality, n (\%) } \\
\hline Death before discharge & $\mathrm{I}, 832(42 \%)$ & $585(48 \%)$ & $270(50 \%)$ & $286(50 \%)$ & $2,973(45 \%)$ \\
\hline
\end{tabular}

Mortality after discharge from hospital was associated with female sex, increasing age, Charlson comorbidity score, and NIV. The risk decreased during the study period. For all patients, the number of previous AECOPD hospitalizations was associated with an increased mortality after discharge compared to no previous hospitalizations with a hazard ratio of 1.32 (95\% CI: 1.19-1.46) with one hospitalization, 1.76 (95\% CI: 1.52-2.02) with two hospitalizations, and 2.07 (95\% CI: 1.80-2.38) with three or more hospitalizations (Figure 3). The risks associated with two and with three or more hospitalizations were significantly higher than the risk associated with one hospitalization ( $P<0.001$ and $P<0.001$, respectively).

The associations with both in-hospital and after-discharge mortality showed the same trends, though weaker, when, instead of AECOPD hospitalizations, respiratory hospitalizations were included in the model (Figure 4).

\section{Discussion}

In this study of patients ventilated for COPD for the first time, an increasing number of hospitalizations in the preceding year were associated with increased overall mortality. We found significant odds ratios for in-hospital death ranging from 1.3 to 1.6 with increasing number of hospitalizations with COPD exacerbations within the previous year. To our knowledge, this association has not been studied in this subgroup of patients. A number of studies have examined the association between previous exacerbations and mortality in other COPD subpopulations, and in some of these, the association was far stronger than what we found.

Hospital contact for exacerbation within the previous year was associated with adverse events within a month, odds ratio 3.9 (95\% CI: 1.6-9.9). ${ }^{22}$ Likewise, having had at least two hospitalizations within the previous 2 years was associated with 30 days mortality, odds ratio 3.6 (95\% CI: 2.5-5.2). ${ }^{34}$ Among ICU admitted patients with COPD, two or more exacerbations within the previous year were associated with inhospital mortality, odds ratio 9.1 (95\% CI: 1.02-81.1). ${ }^{11}$ Apart from different outcome measurements, the discrepancy in the magnitude of the correlations might be explained by different case mixes. Patients with end-stage COPD, which presumably have more frequent exacerbations, may to some extent have been excluded from our cohort due to advancement orders that ruled out ventilation. Whether the stage of stable phase COPD modifies the correlation between the number of hospitalizations and short-term mortality needs to be further evaluated.

Among patients with COPD in Denmark, Schmidt et $\mathrm{al}^{35}$ found significant association between neither previous overall exacerbations nor previous hospitalized exacerbations and 30-day mortality after hospitalization for exacerbation upon adjustment for age, sex, comorbidities, and previous medication. Patients in this cohort, in contrast to those included in ours, were dissimilar with regard to the acute severity of the exacerbation due to a case mix of ventilated and nonventilated patients. Moreover, first time and repeated hospitalizations were evaluated together, and redeemed prescriptions for obstructive airway diseases medication were not a criterion for inclusion. Another study of 3-month mortality showed that previous hospitalizations were not a significant predictor of mortality upon inclusion of markers of acute derangement and performance status. ${ }^{36}$ It is possible, though, that the decision of admitting a patient with any given degree of acute illness depends on performance status, thus masking an association between previous hospitalizations and mortality.

Table 3 Mortality after discharge by number of COPD hospitalizations in the previous year

\begin{tabular}{|c|c|c|c|c|c|}
\hline & \multicolumn{4}{|c|}{ Number of admissions in the previous year } & \multirow[b]{2}{*}{ Total } \\
\hline & 0 & $\mathbf{I}$ & 2 & $3+$ & \\
\hline & $n=2,501$ & $\mathrm{n}=\mathbf{6 2 8}$ & $\mathrm{n}=\mathbf{2 6 8}$ & $\mathrm{n}=\mathbf{2 8 6}$ & $n=3,683$ \\
\hline \multicolumn{6}{|l|}{ Mortality } \\
\hline Death within 30 days & $236(9 \%)$ & $99(16 \%)$ & $4 \mathrm{I}(15 \%)$ & $44(15 \%)$ & $420(11 \%)$ \\
\hline Death within I year & 827 (33\%) & $296(47 \%)$ & I 58 (59\%) & $169(59 \%)$ & $\mathrm{I}, 450(39 \%)$ \\
\hline
\end{tabular}




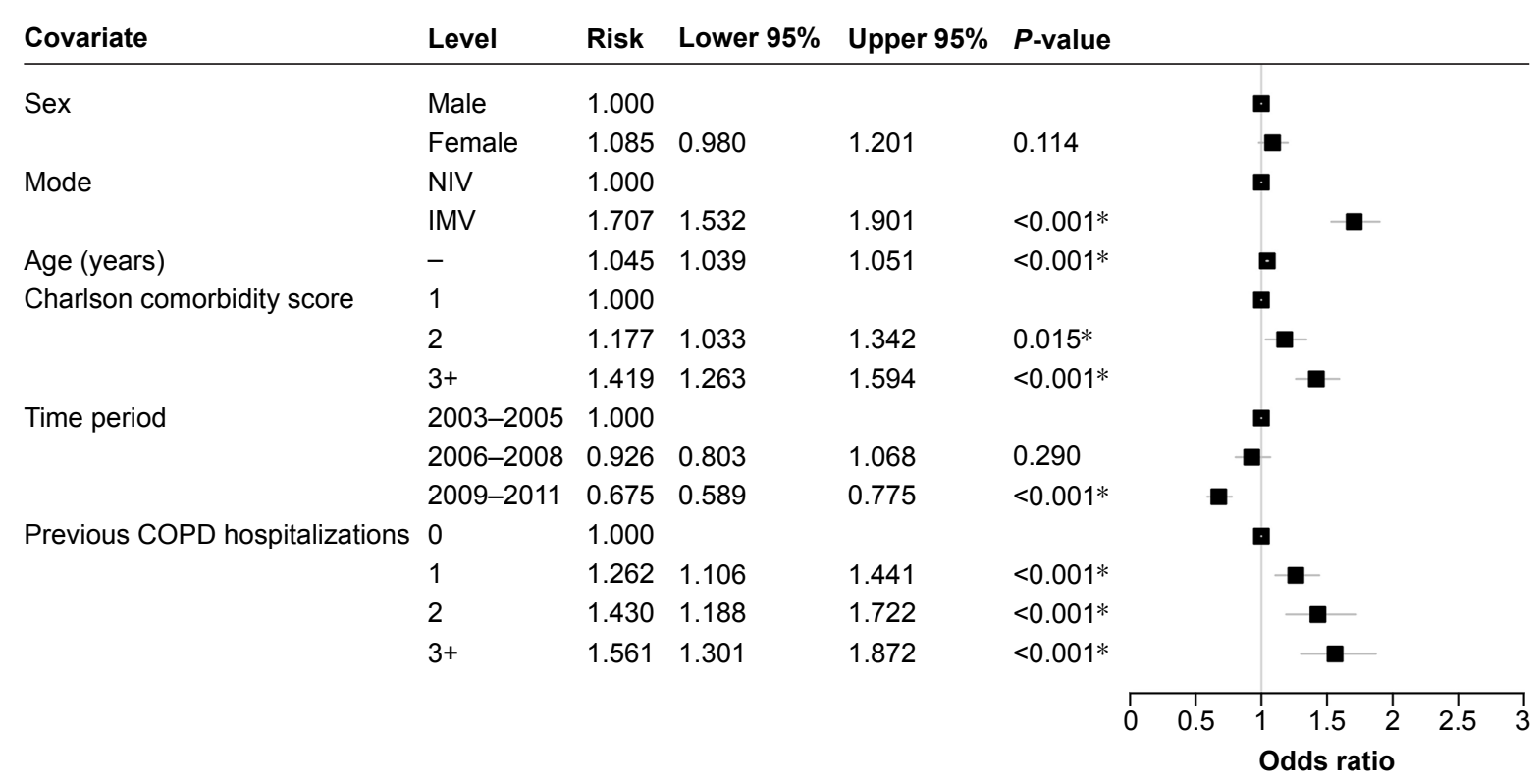

Figure 2 Logistic regression model of in-hospital mortality.

Note: *Significant at $P<0.05$.

Abbreviations: NIV, noninvasive mechanical ventilation; IMV, invasive mechanical ventilation.

In our study population, mortality after discharge was associated with previous exacerbations with hazard ratios in the range of 1.3-2.0 for one and three or more hospitalizations, respectively. The aforementioned Danish study $^{35}$ also found a significant association between longterm mortality and the number of COPD exacerbations. The strength of the association is comparable to what we found and to what was found in a Spanish study. ${ }^{37}$

A large American study ${ }^{38}$ found a lower hazard ratio after discharge of 1.14 by each previous hospitalization in a 1 -year period. However, the inclusion criteria as well as the case mix were profoundly different from ours, and in addition, immortal time bias might partly account for the estimate being lower than ours. No independent association was found in another study by Almagro et al, ${ }^{39}$ but stable phase lung function impairment correlated strongly with prognosis and might have masked an association.

Our study confirmed the importance of age and comorbidity, while sex was only associated with mortality after discharge. Mortality risk decreased with time. IMV as

\begin{tabular}{|c|c|c|c|c|c|c|c|}
\hline Covariate & Level & Risk & Lower 95\% & Upper $95 \%$ & $P$-value & & \\
\hline \multirow[t]{2}{*}{ Sex } & Male & 1.000 & & & & a & \\
\hline & Female & 1.165 & 1.076 & 1.261 & $<0.001 *$ & & $\boldsymbol{\square}$ \\
\hline \multirow[t]{2}{*}{ Mode } & NIV & 1.000 & & & & a & \\
\hline & IMV & 0.768 & 0.705 & 0.837 & $<0.001 *$ & $\mathbf{\square}$ & \\
\hline Age (years) & - & 1.039 & 1.034 & 1.043 & $<0.001 *$ & a & 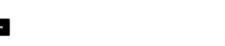 \\
\hline \multirow[t]{3}{*}{ Charlson comorbidity score } & 1 & 1.000 & & & & a & \\
\hline & 2 & 1.278 & 1.153 & 1.417 & $<0.001^{*}$ & & $\square$ \\
\hline & $3+$ & 1.530 & 1.395 & 1.678 & $<0.001 *$ & & - \\
\hline \multirow[t]{3}{*}{ Time period } & 2003-2005 & 1.000 & & & & - & \\
\hline & 2006-2008 & 0.852 & 0.764 & 0.950 & $0.004^{*}$ & - & \\
\hline & 2009-2011 & 0.673 & 0.603 & 0.750 & $<0.001 *$ & 口 & \\
\hline \multirow[t]{6}{*}{ Previous COPD hospitalizations } & 0 & 1.000 & & & & - & 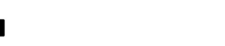 \\
\hline & 1 & 1.317 & 1.188 & 1.460 & $<0.001 *$ & & $\square$ \\
\hline & 2 & 1.755 & 1.524 & 2.021 & $<0.001 *$ & & - \\
\hline & $3+$ & 2.074 & 1.804 & 2.384 & $<0.001 *$ & & $\square$ \\
\hline & & & & & 0 & 0.5 & $\begin{array}{lll}1 & 1 & 1 \\
1.5 & 2 & 2.5\end{array}$ \\
\hline & & & & & & & lazard ratio \\
\hline
\end{tabular}

Figure 3 Cox proportional hazards model of mortality after discharge.

Note: *indicates significant at $P<0.05$.

Abbreviations: NIV, noninvasive mechanical ventilation; IMV, invasive mechanical ventilation. 


\begin{tabular}{|c|c|c|c|c|c|c|c|c|c|c|}
\hline $\mathbf{A}$ & Covariate & Level & Risk & Lower $95 \%$ & Upper $95 \%$ & $P$-value & & & & \\
\hline \multirow{2}{*}{\multicolumn{2}{|c|}{ Sex }} & Male & 1.000 & & & & & a & & \\
\hline & & Female & 1.082 & 0.977 & 1.197 & 0.129 & & a & & \\
\hline \multirow{2}{*}{\multicolumn{2}{|c|}{ Mode }} & NIV & 1.000 & & & & & a & & \\
\hline & & IMV & 1.702 & 1.528 & 1.895 & $<0.001 *$ & & $\square$ & & \\
\hline & Age (years) & - & 1.045 & 1.039 & 1.051 & $<0.001 *$ & & a & & \\
\hline \multirow{3}{*}{\multicolumn{2}{|c|}{ Charlson comorbidity score }} & 1 & 1.000 & & & & & $\mathbf{a}$ & & \\
\hline & & 2 & 1.173 & 1.029 & 1.338 & $0.017^{*}$ & & $\square$ & & \\
\hline & & $3+$ & 1.408 & 1.253 & 1.581 & $<0.001 *$ & & - & & \\
\hline \multirow{3}{*}{\multicolumn{2}{|c|}{ Time period }} & 2003-2005 & 1.000 & & & & & a & & \\
\hline & & $2006-2008$ & 0.926 & 0.803 & 1.068 & 0.291 & & $\mathbf{a}$ & & \\
\hline & & 2009-2011 & 0.674 & 0.587 & 0.773 & $<0.001 *$ & a & & & \\
\hline \multirow{6}{*}{\multicolumn{2}{|c|}{ Previous respiratory hospitalizations }} & 0 & 1.000 & & & & & a & & \\
\hline & & 1 & 1.229 & 1.081 & 1.399 & $0.002 *$ & & - & & \\
\hline & & 2 & 1.389 & 1.163 & 1.658 & $<0.001 *$ & & - & & \\
\hline & & $3+$ & 1.474 & 1.248 & 1.742 & $<0.001 *$ & & $\square$ & & \\
\hline & & & & & & & $\begin{array}{ll} & 1 \\
0 & 0.5\end{array}$ & $\begin{array}{lll}1 & 1 & 1 \\
1 & 1.5 & 2\end{array}$ & 2.5 & 3 \\
\hline & & & & & & & & Odds ratio & & \\
\hline B & Covariate & Level & Risk & Lower $95 \%$ & Upper $95 \%$ & $P$-value & & & & \\
\hline \multirow{2}{*}{\multicolumn{2}{|c|}{ Sex }} & Male & 1.000 & & & & & a & & \\
\hline & & Female & 1.162 & 1.074 & 1.259 & $<0.001 *$ & & - & & \\
\hline \multirow{2}{*}{\multicolumn{2}{|c|}{ Mode }} & NIV & 1.000 & & & & & a & & \\
\hline & & IMV & 0.769 & 0.706 & 0.838 & $<0.001 *$ & a & & & \\
\hline & Age (years) & - & 1.039 & 1.035 & 1.044 & $<0.001 *$ & & a & & \\
\hline \multirow{3}{*}{\multicolumn{2}{|c|}{ Charlson comorbidity score }} & 1 & 1.000 & & & & & a & & \\
\hline & & 2 & 1.272 & 1.147 & 1.411 & $<0.001 *$ & & - & & \\
\hline & & $3+$ & 1.505 & 1.372 & 1.651 & $<0.001 *$ & & a & & \\
\hline \multirow{3}{*}{\multicolumn{2}{|c|}{ Time period }} & $2003-2005$ & 1.000 & & & & & a & & \\
\hline & & $2006-2008$ & 0.861 & 0.772 & 0.960 & $0.007^{*}$ & घ & $\square$ & & \\
\hline & & 2009-2011 & 0.677 & 0.607 & 0.755 & $<0.001 *$ & a & & & \\
\hline \multirow{6}{*}{\multicolumn{2}{|c|}{ Previous respiratory hospitalizations }} & 0 & 1.000 & & & & & a & & \\
\hline & & 1 & 1.287 & 1.163 & 1.423 & $<0.001 *$ & & a & & \\
\hline & & 2 & 1.646 & 1.436 & 1.886 & $<0.001 *$ & & - & & \\
\hline & & $3+$ & 1.982 & 1.746 & 2.251 & $<0.001 *$ & & - & & \\
\hline & & & & & & & $\begin{array}{ll}1 & 1 \\
0 & 0.5\end{array}$ & $\begin{array}{lll}1 & 1 & 1 \\
1 & 1.5 & 2\end{array}$ & 2.5 & 3 \\
\hline & & & & & & & & Hazard ratio & & \\
\hline
\end{tabular}

Figure 4 Respiratory hospitalizations.

Notes: (A) Logistic regression model of in-hospital mortality, (B) Cox proportional hazards model of mortality after discharge. *indicates significant at $P<0.05$. Abbreviations: NIV, noninvasive mechanical ventilation; IMV, invasive mechanical ventilation.

a mode of ventilation predicted death before discharge independently, whereas NIV predicted time to death after discharge. IMV is mainly initiated in patients with severe acute derangement, which probably accounts for the associated higher in-hospital mortality compared to NIV. That this relation is reversed after discharge can have several explanations, among those that patients discharged alive after IMV treatment had undergone harder selection.

In comparison with other studies, our estimate of inhospital mortality of ventilated patients is high, ${ }^{16,31,40}$ but this might partly be explained by inclusion in our study of patients with COPD with pneumonia, which confers a large additional risk. ${ }^{41}$
The association between treatment year and risk might be explained by increasingly aggressive strategies for stable phase medication and for ventilation during exacerbations. Assuming that both medication and ventilation have mainly gained a stronger foothold among less afflicted patients with COPD, gradual rarefication of mortality by the inherently favorable prognosis of this group can explain the improvement of prognosis. ${ }^{42}$

The strengths of our study are the large number of patients and the high reliability of the Danish medical registers, which is well established for a number of diagnoses, ${ }^{43}$ among those the COPD diagnosis applied here (a positive predictive value of $92 \%),{ }^{32}$ procedures,${ }^{44}$ and vital status. ${ }^{45}$ In addition, 
the inherent ability to track unique patient courses virtually eliminates all but emigration as loss to follow-up.

Our study has noteworthy limitations. Misclassification is in our data set especially problematic with regard to the calculated comorbidity, where completeness of registration will be highest among frequently hospitalized patients. However, the use of Charlson comorbidity score has been shown to yield acceptable precision when calculated from registers ${ }^{46}$ although the sensitivity of secondary diagnoses in the National Patient Registry is known to be low. ${ }^{47} \mathrm{We}$ speculated whether the number of previous hospitalizations decided by our method could underestimate the number of hospitalizations as the propensity to register a COPD diagnosis in connection with a hospitalization might depend on the COPD stage. Such misclassification might even be differential as only previously admitted patients could be misclassified. To test this, we substituted respiratory hospitalizations for COPD hospitalizations, which did not materially change the results.

We chose to include only patients with COPD who had redeemed prescriptions for obstructive airway diseases medication within the year preceding ventilation. This excluded $49 \%$ of all patients whose hospitalizations would have qualified as index hospitalizations. This might reflect not only low compliance but also the inclusion of patients with breathing difficulties whose history was suggestive of COPD but who did not have symptoms on a daily basis. It is surprising and concerning that the proportion of patients who had not redeemed medication was almost equal in patients who had no previous admissions and in patients who had been repeatedly hospitalized. Exclusion in this case is a trade-off between generalizability and validity. It is generally assumed that previous medication acts as a proxy for previously recognized COPD, and thereby to some extent as a marker of stable phase disease severity. Previously, it has been shown that majority of the COPD population are unaware of their disease ${ }^{48}$ and that a considerable proportion of even patients with advanced disease $(25 \%)$ do not receive appropriate treatment. ${ }^{49}$ Even so, in general, the unrecognized cases have less advanced disease, are hospitalized less frequently after the hospitalization where the diagnosis was established, ${ }^{50}$ and have less severe symptoms prior to exacerbations. ${ }^{50}$

Other limitations to our study are the lack of information on lung function prior to the hospitalization, the degree of acute physiological derangement, and the extent of limitations in care. Differences in underlying acute and chronic lung function impairment might confound the association between previous hospitalizations and mortality. However, we do consider this to be partly ameliorated by the inclusion of only such patients as had been offered ventilation upon clinical decision. Wildman et al ${ }^{51}$ have shown that clinicians are overly pessimistic when predicting the survival of patients with COPD on hospitalization to specialized respiratory units or ICUs, so it must be assumed that the instigation of assisted ventilation, at least invasive ventilation, among patients with very severe lung function impairment is limited. As for variation in severity of present respiratory failure, any subject hospitalized to our selected study population had an overall acute derangement warranting assisted ventilation, and it must be assumed that the gas exchange was considerably impaired in most of our subjects. In pace with the dissemination of NIV as an accessible treatment option, NIV has to some extent become the interventional limit for a group of frail, elderly patients with often advanced COPD. ${ }^{19}$ We did not have access to information on do-not-intubateorders, but a previous Danish study found such orders in $10 \%$ of NIV patients. ${ }^{52}$ Presumably, a subpopulation of patients with short expected life span diluted the survival in the NIV group.

\section{Conclusion}

In conclusion, among the patients with COPD with acute exacerbation treated with assisted ventilation for the first time, the number of hospitalizations for COPD in the preceding year is associated with increased mortality in-hospital as well as after discharge. Our study did not aim at identifying patients in whom assisted ventilation is futile. Nonetheless, it emphasizes the importance of the clinical trajectory for the outcome following ventilation in a group of patients whose mortality is very high.

\section{Author contributions}

APTP had full access to all of the data in the study and takes responsibility for the integrity of the data and the accuracy of the data analysis. CTP, UMW, and BSR contributed substantially to the study design, data analysis and interpretation, and the writing of the manuscript. All authors contributed toward data analysis, drafting and critically revising the paper and agree to be accountable for all aspects of the work.

\section{Disclosure}

The authors report no conflicts of interest in this work.

\section{References}

1. Global Initiative for Chronic Obstructive Lung Disease. Global Strategy for the Diagnosis, Management, and Prevention of Chronic Obstructive Pulmonary Disease. 2015. 
2. Kruis AL, Ställberg B, Jones RCM, et al. Primary care COPD patients compared with large pharmaceutically-sponsored COPD studies: an UNLOCK validation study. PLoS One. 2014;9(3).

3. Müllerova H, Maselli DJ, Locantore N, et al; ECLIPSE Investigators. Hospitalized exacerbations of COPD. CHEST J. 2015;147(4): 999.

4. Hurst JR, Vestbo J, Anzueto A, et al; Evaluation of COPD Longitudinally to Identify Predictive Surrogate Endpoints (ECLIPSE) Investigators. Susceptibility to exacerbation in chronic obstructive pulmonary disease. $N$ Engl J Med. 2010;363(12):1128-1138.

5. Garcia-Aymerich J, Serra Pons I, Mannino DM, Maas AK, Miller DP, Davis KJ. Lung function impairment, COPD hospitalisations and subsequent mortality. Thorax. 2011;66(7):585-590.

6. Vestbo J, Agusti A, Wouters EFM, et al. Should we view chronic obstructive pulmonary disease differently after ECLIPSE? A clinical perspective from the study team. Am J Respir Crit Care Med. 2014;189(9): $1022-1030$

7. Han MK, Agusti A, Calverley PM, et al. Chronic obstructive pulmonary disease phenotypes: the future of COPD. Am J Respir Crit Care Med. 2010;182(5):598-604.

8. Soler-Cataluña JJ, Martínez-García MA, Román Sánchez P, Salcedo E, Navarro M, Ochando R. Severe acute exacerbations and mortality in patients with chronic obstructive pulmonary disease. Thorax. 2005;60(11):925-931.

9. Johannesdottir SA, Christiansen CF, Johansen MB, et al. Hospitalization with acute exacerbation of chronic obstructive pulmonary disease and associated health resource utilization: a population-based Danish cohort study. J Med Econ. 2013;16(7):897-906.

10. Suissa S, Dell'Aniello S, Ernst P. Long-term natural history of chronic obstructive pulmonary disease: severe exacerbations and mortality. Thorax. 2012;67(11):957-963.

11. Aburto M, Esteban C, Moraza FJ, Aguirre U, Egurrola M, Capelastegui A. COPD exacerbation: mortality prognosis factors in a respiratory care unit. Arch Bronconeumol. 2011;47(2):79-84.

12. Singanayagam A, Schembri S, Chalmers JD. Predictors of mortality in hospitalized adults with acute exacerbation of chronic obstructive pulmonary disease. A systematic review and meta-analysis. Ann Am Thorac Soc. 2013;10(2):81-89.

13. Eriksen N, Hansen EF, Munch EP, Rasmussen FV, Vestbo J. [Chronic obstructive pulmonary disease. Admission, course and prognosis]. Ugeskr Laeger. 2003;165(37):3499-3502.

14. Batzlaff CM, Karpman C, Afessa B, Benzo RP. Predicting 1-year mortality rate for patients admitted with an acute exacerbation of chronic obstructive pulmonary disease to an intensive care unit: an opportunity for palliative care. Mayo Clin Proc. 2014;89(5):638-643.

15. Messer B, Griffiths J, Baudouin SV. The prognostic variables predictive of mortality in patients with an exacerbation of COPD admitted to the ICU: an integrative review. QJM. 2012;105(2):115-126.

16. Lindenauer PK, Stefan MS, Shieh M-S, Pekow PS, Rothberg MB, Hill NS. Outcomes associated with invasive and noninvasive ventilation among patients hospitalized with exacerbations of chronic obstructive pulmonary disease. JAMA Intern Med. 2014:1-12.

17. Stefan MS, Nathanson BH, Higgins TL, et al. Comparative effectiveness of noninvasive and invasive ventilation in critically III patients with acute exacerbation of chronic obstructive pulmonary disease. Crit Care Med. 2015:1.

18. Chandra D, Stamm JA, Taylor B, et al. Outcomes of noninvasive ventilation for acute exacerbations of chronic obstructive pulmonary disease in the United States, 1998-2008. Am J Respir Crit Care Med. 2012;185(2):152-159.

19. Roberts CM, Stone RA, Buckingham RJ, Pursey NA, Lowe D; National Chronic Obstructive Pulmonary Disease Resources and Outcomes Project Implementation Group. Acidosis, non-invasive ventilation and mortality in hospitalised COPD exacerbations. Thorax. 2011; 66(1):43-48.
20. Dres M, Tran T-C, Aegerter P, et al. Influence of ICU case-volume on the management and hospital outcomes of acute exacerbations of chronic obstructive pulmonary disease. Crit Care Med. 2013;41(8): 1884-1892.

21. Ho T-W, Tsai Y-J, Ruan S-Y; HINT StudyGroup. In-hospital and oneyear mortality and their predictors in patients hospitalized for first-ever chronic obstructive pulmonary disease exacerbations: a nationwide population-based study. PLoS One. 2014;9(12):e114866.

22. Matkovic Z, Huerta A, Soler N, et al. Predictors of adverse outcome in patients hospitalised for exacerbation of chronic obstructive pulmonary disease. Respiration. 2012;84(1):17-26.

23. Lange P, Marott JL, Vestbo J, et al. Prediction of the clinical course of chronic obstructive pulmonary disease, using the new GOLD classification: a study of the general population. Am J Respir Crit Care Med. 2012;186(10):975-981.

24. Terzano C, Conti V, Di Stefano F, et al. Comorbidity, hospitalization, and mortality in COPD: results from a longitudinal study. Lung. 2010; 188(4):321-329.

25. Ucgun I, Metintas M, Moral H, Alatas F, Yildirim H, Erginel S. Predictors of hospital outcome and intubation in COPD patients admitted to the respiratory ICU for acute hypercapnic respiratory failure. Respir Med. 2006;100(1):66-74.

26. Afessa B, Morales IJ, Scanlon PD, Peters SG. Prognostic factors, clinical course, and hospital outcome of patients with chronic obstructive pulmonary disease admitted to an intensive care unit for acute respiratory failure. Crit Care Med. 2002;30(7):1610-1615.

27. Christensen S, Rasmussen L, Horváth-Puhó E, Lenler-Petersen P, Rhode M, Johnsen SP. Arterial blood gas derangement and level of comorbidity are not predictors of long-term mortality of COPD patients treated with mechanical ventilation. Eur J Anaesthesiol. 2008;25(7):550-556.

28. Berkius J, Sundh J, Nilholm L, Fredrikson M, Walther SM. Long-term survival according to ventilation mode in acute respiratory failure secondary to chronic obstructive pulmonary disease: a multicenter, inception cohort study. J Crit Care. 2010;25(3):539.e13-539.e18.

29. Groenewegen KH, Schols AMWJ, Wouters EFM. Mortality and mortality-related factors after hospitalization for acute exacerbation of COPD. Chest. 2003;124(2):459-467.

30. Breen D, Churches T, Hawker F, Torzillo PJ. Acute respiratory failure secondary to chronic obstructive pulmonary disease treated in the intensive care unit: a long term follow up study. Thorax. 2002;57(1):29-33.

31. Nevins ML, Epstein SK. Predictors of outcome for patients with COPD requiring invasive mechanical ventilation. Chest. 2001;119(6): 1840-1849.

32. Thomsen RW, Lange P, Hellquist B, et al. Validity and underrecording of diagnosis of COPD in the Danish National Patient Registry. Respir Med. 2011;105(7):1063-1068.

33. Radovanovic D, Seifert B, Urban P, et al. Validity of Charlson Comorbidity Index in patients hospitalised with acute coronary syndrome. Insights from the nationwide AMIS Plus registry 2002-2012. Heart. 2014;100:288-294.

34. Faustini A, Marino C, D'Ippoliti D, Forastiere F, Belleudi V, Perucci CA. The impact on risk-factor analysis of different mortality outcomes in COPD patients. Eur Respir J. 2008;32(3):629-636.

35. Schmidt SAJ, Johansen MB, Olsen M, et al. The impact of exacerbation frequency on mortality following acute exacerbations of COPD: a registry-based cohort study. BMJ Open. 2014;4:e006720-e006720.

36. Roberts CM, Lowe D, Bucknall CE, Ryland I, Kelly Y, Pearson MG. Clinical audit indicators of outcome following admission to hospital with acute exacerbation of chronic obstructive pulmonary disease. Thorax. 2002;57:137-141.

37. Almagro P, Calbo E, Ochoa de Echagüen A, et al. Mortality after hospitalization for COPD. Chest. 2002;121(5):1441-1448.

38. McGhan R, Radcliff T, Fish R, Sutherland ER, Welsh C, Make B. Predictors of rehospitalization and death after a severe exacerbation of COPD. Chest. 2007;132(6):1748-1755. 
39. Almagro P, Cabrera FJ, Diez J, et al. Comorbidities and short-term prognosis in patients hospitalized for acute exacerbation of COPD: the EPOC en Servicios de medicina interna (ESMI) study. Chest. 2012; 142(5):1126-1133.

40. Ai-Ping C, Lee K-H, Lim T-K. In-hospital and 5-year mortality of patients treated in the ICU for acute exacerbation of COPD: a retrospective study. Chest. 2005;128(2):518-524.

41. Ongel EA, Karakurt Z, Salturk C, et al. How do COPD comorbidities affect ICU outcomes? Int J Chron Obstruct Pulmon Dis. 2014;9: 1187-1196.

42. Lindenauer PK, Lagu T, Shieh MS, Pekow PS, Rothberg MB. Association of diagnostic coding with trends in hospitalizations and mortality of patients with pneumonia, 2003-2009. JAMA J Am Med Assoc. 2012; 307(13):1405.

43. Thygesen SK, Christiansen CF, Christensen S, Lash TL, Sørensen HT. The predictive value of ICD-10 diagnostic coding used to assess Charlson comorbidity index conditions in the population-based Danish National Registry of Patients. BMC Med Res Methodol. 2011; 11(1):83.

44. Blichert-Hansen L, Nielsson MS, Nielsen RB, Christiansen CF, Nørgaard M. Validity of the coding for intensive care admission, mechanical ventilation, and acute dialysis in the Danish National Patient Registry: a short report. Clin Epidemiol. 2013;5:9-12.

45. Schmidt M, Pedersen L, Sørensen HT. The Danish Civil Registration System as a tool in epidemiology. Eur J Epidemiol. 2014;29(8): 541-549.
46. Quan H, Parsons GA, Ghali WA. Validity of information on comorbidity derived rom ICD-9-CCM administrative data. Med Care. 2002;40(8): 675-685.

47. Kümler T, Gislason GH, Kirk V, et al. Accuracy of a heart failure diagnosis in administrative registers. Eur J Heart Fail. 2008;10(7): 658-660.

48. Soriano JB, Zielinski J, Price D. Screening for and early detection of chronic obstructive pulmonary disease. Lancet. 2009;374(9691): $721-732$.

49. Hansen JG, Pedersen L, Overvad K, Omland Ø, Jensen HK, Sørensen HT. The Prevalence of chronic obstructive pulmonary disease among Danes aged 45-84 years: population-based study. COPD. 2008; 5(6):347-352.

50. Balcells E, Gimeno-Santos E, de Batlle J, et al. Characterisation and prognosis of undiagnosed chronic obstructive pulmonary disease patients at their first hospitalisation. BMC Pulm Med. 2015;15(1):4.

51. Wildman MJ, Sanderson C, Groves J, et al. Implications of prognostic pessimism in patients with chronic obstructive pulmonary disease (COPD) or asthma admitted to intensive care in the UK within the COPD and asthma outcome study (CAOS): multicentre observational cohort study. BMJ. 2007;335(7630):1132.

52. Titlestad IL, Lassen AT, Vestbo J. Long-term survival for COPD patients receiving noninvasive ventilation for acute respiratory failure Int J Chron Obstruct Pulmon Dis. 2013;8:215-219.
International Journal of COPD

\section{Publish your work in this journal}

The International Journal of COPD is an international, peer-reviewed journal of therapeutics and pharmacology focusing on concise rapid reporting of clinical studies and reviews in COPD. Special focus is given to the pathophysiological processes underlying the disease, intervention programs, patient focused education, and self management protocols.

\section{Dovepress}

This journal is indexed on PubMed Central, MedLine and CAS. The manuscript management system is completely online and includes a very quick and fair peer-review system, which is all easy to use. Visit http://www.dovepress.com/testimonials.php to read real quotes from published authors. 